\title{
Tinjauan Teologis Tentang Pendidikan Kristiani Multikultural
}

\author{
Hery Susanto \\ Sekolah Tinggi Teologi Jemaat Kristus Indonesia \\ Email: kristocarly@gmail.com
}

\begin{abstract}
Multicultural Christian education is in line with the diversity that exists in Indonesia. Theologically, Christian education contains elements of knowing God which is universal so that it is not only controlled by the Jews. In the Jewish tradition Christian education was intense, but Jesus extended that teaching beyond the boundaries of Jewish culture and tradition. The culture used is the culture of God's kingdom that puts forward the power of God's government in the world and heaven. In every human culture, there is always room for religiosity, and that is what must be taught. The Lord Jesus teaches anyone to be able to know God's Kingdom and His will in human culture. The method used is a literature qualitative research method by comparing various sources of writing related to multicultural Christian education and its implementation in Christian education in Indonesian culture.
\end{abstract}

Keywords: Educational, Christian, Multicultural, Universal

\begin{abstract}
Abstrak
Pendidikan kristiani multikultural sangat sesuai dengan keberagaman yang ada di Indonesia. Secara teologis, pendidikan Kristiani mengandung unsur pengenalan akan Tuhan yang universal sehingga bukan hanya dikuasai oleh orang Yahudi saja. Dalam tradisi Yahudi pendidikan kristiani sangan intens, tetapi Yesus mengembangkan pengajaran itu melampaui batasan budaya dan tradisi Yahudi. Budaya yang digunakan adalah budaya kerajaan Allah yang lebih menekankan kuasa pemerintahan Allah di dalam dunia dan di surga. Setiap budaya manusia selalu memberi ruang bagi religiusitas, dan itulah yang harus diajarkan. Tuhan Yesus mengajarkan kepada siapapun untuk dapat mengenal Kerajaan Allah dan kehendak-Nya dalam budaya manusia. Metode yang digunakan adalah metode penelitian kualitatif literature dengan membandingkan berbagai sumber tulisan yang terkait dengan pendidikan kristiani multikultur dan implementasinya dalam pendidikan kristiani dalam budaya masyarakat Indonesia.
\end{abstract}

Kata Kunci: Pendidikan, Kristiani, Multikultural, Universal

\section{PENDAHULUAN}

Pendidikan Kristiani merupakan

bagian dari tugas murid Kristus untuk mengajarkan kepada para pengikut

Kristus lainnya. Yesus bukan

mengajarkan agama tetapi kehidupan 
yang 'kristiani'. Keberadaan Yesus selalu hadir di tengah masyarakat yang beragam latar belakang budaya dan agama. Kekristenan adalah untuk semua orang yang mau menerima Yesus sebagai Tuhan dan Juruselamat dalam hidupnya. Keberadaan-Nya di dunia adalah untuk semua manusia. Yesus memiliki berbagai metode yang digunakan untuk mengajarkannya, misalnya melalui perumpamaan, mujizat, dialog, tanya jawab dan penjelasan secara eksplisit.

Beberapa artikel sebelumnya telah membahas mengenai topik yang hampir sama. Dalam sebuah artikel yang ditulis sebelumnya oleh I Made Suardana mengatakan bahwa PAK secara konseptual harus menempatkan konteks Indonesia sebagai sikap menghargai terhadap kehidupan bersama di Indonesia yang multikultur (Suardana, 2020). Pembahasan menekankan landasan konseptualnya dalam melakukan PAK.

I Putu Ayub Darmawan juga menulis bahwa pembentukan komunitas iman kepada Yesus Kristus melalui pemuridan juga merupakan tugas yang multikultur, artinya tidak membedabedakan seseorang (Darmawan, 2019). Penekanan dalam artikel ini lebih kepada pembentukan komunitas imannya kepada Yesus yang justru merangkul keberagaman kultur individu sebagai satu komunitas iman.
Tulisan dalam artikel kali ini mengangkat sisi lain dari pendidikan kristiani multikultur yaitu dari sudut teologis dan teladan Yesus. Latar belakang masalah dalam artikel ini adalah adanya kecenderungan bahwa pendidikan Kristen mengarah kepada pengajaran agama yang bersifat kompetitif tentang benar dan salah, sementara itu di dalam ajaran Yesus selalu merangkul semua orang masuk dalam kerajaan Allah. Oleh sebab itu pendidikan kristiani seharusnya bersifat universal dan multikultur.

Dalam penelitian sebelumnya dikatakan bahwa dalam konteks Indonesia, pendidikan multikultural sudah menjadi sesuatu hal yang mutlak. Di dalamnya, keberagaman bukan menjadi satu penghalang atau sumber perpecahan, sebaliknya memberikan dorongan yang baik bagi kemajuan bersama sebagai bangsa (Wasitohadi, 2012).

Tujuan dari pembahasan artikel ini adalah membahas dari sisi teologis bahwa pendidikan kristiani multikultural juga dilakukan dan diajarkan oleh Tuhan Yesus kepada semua murid-Nya. Sikap fanatisme dan eksklusif bukan mencerminkan sifat pendidikan kristiani melalui berbagai sumber literatur yang mendukung. Langkah awal yang dilakukan adalah dengan menentukan 
penilaian, bahwa dalam praksis, pendidikan kristiani dalam konteks Indonesia secara khusus dan dunia timur secara umum sudah seharusnya memperhatikan keperbedaan dan keberagaman menjadi ladang subur bagi pendidikan. Penggunaan literatur website dan artikel jurnal terkait menjadi data yang disajikan secara deskriptif dan dianalisis dengan kajian teologis.

\section{METODE PENELITIAN}

Tulisan ini merupakan penelitian kualitatif literature, dengan menerapkan metode analisis dan refleksi kritis tinjauan teologis terhadap pendidikan kristiani multikultur berdasar tulisantulisan terkait, dan mengolah beberapa isu penting tentang esensi pendidikan kristiani berdasarkan Alkitab yang dibatasi oleh topik tertentu seperti: Pola pendidikan Yahudi, cara Yesus mengajar murid-murid-Nya, implikasinya bagi pendidikan kristiani dalam konteks budaya lokal di Indonesia. Sumber yang relevan pembahasan artikel ini diantaranya adalah dari buku Kerangka Teologi Religionum Misioner (Siburian, 2004), Jesus Without Borders (Green, 2015) dan The Church from Every Tribe and Tongue (Perdue, 2018).
PEMBAHASAN DAN HASIL

Konsientisasi atau penyadaran menurut Paulo Freire, adalah membuka kesadaran peserta didik atas keberadaan ketertindasannya sehingga dapat melakukan transformasi sosial. Konsientisasi menjadi sebuah nama proses penyadaran kritis atas berbagai komponen sejarah yang mempengaruhi hidup seseorang sehingga dapat memunculkan potensi-potensi yang merdeka dan kreatif. Selain menyadari komponen tersebut, juga ada gerakan menuju pembebasan dalam diri pribadi, masyarakat dan komunitasnya (McKenna, 2013). Jadi di dalam pendidikan menurut Freire selalu berkaitan dengan sikap dan tindakan politik, untuk mempertahankan status quo atau untuk membuat suatu perubahan sosial.

Hakikat Pendidikan Kristiani dalam konteks masyarakat yang multikultur, dapat ditinjau dari dua sisi. Sisi Pendidikan dan sisi teologi.

Dari sisi pendidikan, pembelajar memahami dan menghargai kemajemukan masyarakatnya, menghormati hak hidup setiap agama dan budaya. Pendidikan multikultural mengandung beberapa nilai utama, yaitu: mampu menghargai atau mengapresiasi budaya yang beragam, menghormati dan menjunjung tinggi hak asasi manusia, 
pengembangan sikap bertanggung jawab bagi masyarakat di dunia.

Dalam proses pendidikan multikultural terdapat capaian-capaian penting sebagai tujuannya yaitu:

- Mengembangkan kesadaran diri dari kelompok-kelompok masyarakat,

- Meningkatkan kesadaran budaya masyarakat,

- Memperkuat kompetensi interkultural budaya-budaya masyarakat,

- Menghilangkan ketidakadilan rasisme dan prasangka buruk (negative pre-assumption),

- Mengembangkan sense of belonging terhadap bumi,

- Mengembangkan ketersediaan dan kemampuan dalam pengembangan masayarakat (Wasitohadi, 2012).

Dari sisi teologis, pendidikan kristiani mengajarkan kearifan hidup sesuai dengan nilai-nilai kekristenan yang diajarkan oleh Yesus. Pendidikan kristiani wajib menekankan pentingnya memfokuskan diri pada kebutuhan akan perubahan dan sosial kultural kontekstual (life issues) didukung oleh ilmu-ilmu sosial (psikologi dan sosiologi) dengan dasar Alkitab dan teologi yang tepat (Kurniawati, 2014).

Menurut James Banks, pendidikan multikultural merupakan suatu sistem kelompok budaya sebagai tolok ukur. Pendidikan multicultural merupakan sistem pembelajaran dan keterlibatan berbagai disiplin ilmu dengan tujuan utama untuk mencapai kesetaraan kesempatan pendidikan dari berbagai macam murid baik ras, etnik, kelompok soial ekonomi tertentu dan budaya yang beragam (Banks, 2015).

Jadi tujuan pencapaian utama pendidikan multikultural adalah memperkaya wawasan berpikir peserta didik agar lebih terbuka terhadap budaya, suku, ras, dan agama di luar budaya, suku, ras dan agamanya sendiri dengan baik. Sikap ini sesuai dengan konteks manusia Indonesia yang majemuk. Sesuai dengan asas dasar Indonesia yaitu Pancasila, maka kehidupan manusia yang toleran harus dijaga. Dalam hal ini, para peserta didik ditantang untuk mampu berpikir, mengkolaborasi, dan merekonstruksi pemahaman dan pengetahuan tentang kemajemukan budaya, agama, suku, dari perspektif ajaran Yesus.

Menurut Hadi Nurcahyono dalam tulisannya di Jurnal Habitus, praktik pendidikan melting pot adalah penerapan pendidikan multikultur yang mana setiap kelompok etnis dan budaya menyadari adanya perbedaan di antara mereka tetapi dapat membina hidup bersama (Nurcahyono, 2018). Keberagaman 
bukan menjadi penghalang tetapi justru menjadi warna yang indah bagi pendidikan kristiani agar tetap bisa berasimilasi dan menerapkan nilai-nilai luhur pendidikan kristiani ini dalam konteks budaya masing-masing.

Westerhoff menyatakan bahwa kualitas iman yang memadai memungkinkan seseorang tumbuh dalam relasinya dengan Allah, sesama manusia dan alam sekitarnya, bukan dalam ikatan keluarga sosial kultural, tetapi dalam ikatan keluarga iman (John F. Westerhoff, 1976). Jika iman menyatukan manusia melampaui berbagai perbedaan maka perbedaan kulturalpun bukan lagi menjadi masalah. Yang menjadi masalah adalah ketika manusia menjadi saling tarik menarik, memaksakan pahamnya kepada orang lain tanpa dasar kasih dan iman yang tulus.

Dalam beberapa peristiwa di dalam Alkitab, memunculkan sikap Yesus dalam Perjanjian Baru terhadap ikatan keluarga sosial-kultural yang ia perhadapmukakan dengan ikatan keluarga iman (Yesus berumur dua belas tahun dalam Bait Allah - Lukas 2:41-52; Pesta kawin di Kana - Yohanes 2:1-11; Yesus dan saudara-saudaranya- Markus 3:31-35; Yesus membawa pemisahan Matius 10:37-39). Yesus menempatkan ikatan keluarga iman itu mengatasi ikatan keluarga sosial kultural. Ini merupakan dasar bahwa Yesus lebih mengutamakan sikap inklusif bagi siapapun yang mau datang kepada-Nya bukan sekedar kelompoknya sendiri. Yesus menawarkan keselamatan kepada siapapun yang bersedia, tanpa memilihmilih suku, etnis, budaya. Kasih Allah bersifat universal.

Lebih lanjut dicontohkan bahwa tindakan mengasihi belum tentu menunjukkan bahwa itu perbuatan yang bercirikan kristiani. Perbuatan mengasihi menjadi kristiani jika yang dilakukan adalah penerusan kasih Tuhan Yesus atau motivasi utamanya adalah karena kita sudah lebih dahulu dikasihi oleh-Nya. Sebagaimana di dalam Yohanes 15:12 mengatakan," Inilah perintah-Ku, yaitu supaya kamu saling mengasihi, seperti Aku telah mengasihi kamu." Kualitas yang sama dengan apa yang Tuhan telah lakukan (Sairin, 2000). Tindakan mengasihi dengan meneladani kasih Allah adalah memberikan nuansa yang berbeda karena kasih itu menjadi penerusan kasih Yesus kepada semua manusia tanpa membeda-bedakan bahkan mau berkorban untuk orang lain.

\section{Pendidikan dalam Tradisi Yahudi}

Dalam tulisan Eirene Mary, pelaksanaan pendidikan kristiani di dalam hukum Taurat selalu dimulai 
dalam keluarga. Orang tua harus mengajar anak-anaknya dan anak-anak harus hormat kepada orang tuanya (Ulangan 5:16). Hal yang diajarkan adalah tentang perbuatan Allah yang dilakukan bagi manusia secara turun menurun (Mary, 2020). Secara jelas dapat dikatakan bahwa kekuatan ikatan iman di dalam keluarga menjadi sumber utama dalam praktek hidup sosial masyarakat Yahudi.

Menurut dokumen rabinik (Mishna) Yahudi dari abad pertama menguraikan bahwa setiap anak pada umur lima tahun, harus mulai diperkenalkan dengan kitab Torah. Kemudian pada umur sepuluh tahun mereka sudah bisa menghafalkan kitab torah secara lesan (Oral Tora); Kemudian pada usia tiga belas tahun mereka belajar di Bar Mitswa atau istilah sekarang seminari; pada umur lima belas tahun, halakhot atau keputusan para rabi untuk meluluskannya atau tidak. Pada usia delapan belas tahun sudah dipersiapkan untuk menikah; mencari pekerjaan; dan pada umur tiga puluh tahun memasuki masa dewasa penuh. "Cara mendidik anak dalam tradisi Yahudi dimulai sejak jaman Musa di mana orang tua selalu mengkaitkan pendidikan dengan religiusitas mereka". (Ulangan. 6:4-9).
Menurut I Putu Ayub Darmawan, pendidikan religius ini dilakukan dengan metode yang menarik yaitu dengan pengulangan secara verbal dan melalui simbol-simbol yang diikatkan di tiang pintu agar mudah dilihat dan diingat $(\mathrm{P}$. A. Darmawan, 2019). Metode menalikan atau mengikatkan taurat Tuhan serta memperkatakannya berulang-ulang mengekspresikan bahwa taurat dan kehidupan mereka tidak terpisahkan satu sama lain (Rantesalu, 2018). Cara pendidikannya juga meniru sistem pendidikan pagan yang disesuaikan dengan pendidikan dalam Bait Allah. Tradisi ini dilestarikan secara turun temurun dari generasi ke generasi berikutnya sehingga mereka mewarisi tradisi iman yang sangat kuat. Pengalaman langsung mereka dengan TUHAN memberikan kekuatan tersendiri bagi mereka untuk menghayati eksistensi TUHAN dalam perintah dan karya-Nya.

Pendidikan sangat bernilai tinggi bagi orang Yahudi sehingga anak-anak Yahudi terlatih dan terasah secara keilmuan atau kognitifnya dan juga etika moralitas religius mereka karena itu menjadi penekanan utama mereka. Sehingga sebelum filsafat Yunani muncul, relijiusitas dan intelektual orang Yahudi sudah di atas rata-rata. Sikap menjunjung tinggi pendidikan moral dan 
iman ini menghasilkan orang-orang yang militan dan nasionalisme tinggi sehingga sumber Taurat itu menjadi rujukan semua ilmu mereka.

Sistem pendidikan bangsa Yahudi menurut Talmud, satu orang guru boleh menangani dua puluh orang murid. Jika lebih dari itu dapat ditambah seorang guru lagi atau asisten pembantu guru. Guru-guru tersebut mengajar di sinagogsinagog yang dibangun seperti sekolahsekolah untuk belajar.

Di setiap sinagog, terdapat Beth Sepher yang merupakan sekolah dasar dan Beth Midrash sebagai sekolah lanjutan. Beth Midrash ini hanya diikuti oleh murid-murid yang benar-benar pintar dan mampu untuk belajar lebih mendalam. Lulusannya akan menjadi seorang rabbi atau guru yang terhormat di kalangan terpelajar orang Yahudi. Konsep yang menarik adalah pada masa abad pertama masehi, sinagog selain menjadi tempat belajar juga difungsikan sebagai tempat beribadah bagi orang Yahudi. Mengapa demikian? Karena belajar dan ibadah memiliki nilai yang setara. Jika seseorang belajar tapi tidak beribadah maka dikatakan bahwa dirinya tidak belajar. Amsal 1:7, mengatakan, "Takut akan Tuhan adalah awal dari pengetahuan". Jadi keduanya selalu terkait dan tidak dapat dipisahkan.
Pada masa Yesus, seorang Rabbi dihargai setara dengan imam. Orangorang Farisi dan Saduki dianggap sebagai orang-orang ahli di bidang Taurat sehingga kedudukannya sangat dihargai di kalangan masyarakat Yahudi. Yesus juga dihargai oleh mereka karena Dia bukan sekedar rabbi tetapi juga nabi, Dia mengajar dengan penuh kuasa, bukan sekedar mengajar biasa tetapi juga melakukan berbagai mujizat yang belum pernah mereka lihat sebelumnya dari para ahli Taurat lainnya. Itu sebabnya golongan Farisi dan Saduki merasa terancam kedudukannya karena Yesus membukakan mata mereka tentang kebenaran yang baru. Sumbernya sama tetapi cara mengungkapkannya dan menafsirkannya sangat berbeda. Yesus tidak sekedar mengajarkan ilmu, tetapi mampu mentransformasi kehidupan seseorang dengan caranya yang ajaib.

Sasaran dari pengajaran Yesus adalah adanya transformasi hidup bagi para pendengarnya dan mereka menjadi percaya kepada Kristus sebagai Mesias sehingga mereka mendapatkan pengampunan dosa. Sebagai bukti pengampunan dosa, seringkali diukur dari kemampuan mereka mengendalikan diri, melalui perkataan dan perbuatan yang berubah. 
Di samping itu, pendidikan dalam tradisi Yahudi, khususnya Yesus selalu bersifat dinamis, di segala tempat, kepada segala macam jenis manusia, dan tidak terbatas untuk orang-orang Yahudi saja.

Pengetahuan itu bersifat personal. Kebenaran adalah suatu pribadi (Allah), dan pengetahuan akan Allah adalah pribadi juga. Implikasinya adalah bahwa kita harus mengenal Allah dan manusia dalam aspek personal (Nugroho, 2020). Lebih lanjut dapat dikatakan bahwa pengetahuan itu juga bersifat relasional. Hubungan yang erat antara Allah dan umat juga berkaitan dengan ciri kasih, kepedulian, perhatian dan tanggung jawab. Yesus selalu menekankan hubungan yang sehat dan erat antara Tuhan dan manusia.

Karakteristik relasional dalam pendidikan Kristen mengedepankan hubungan antara Allah dan manusia, manusia dan sesama secara seimbang. Estep mengatakan: Pribadi dalam trinitas adalah hubungan antara satu dengan lainnya di mana Allah telah menciptakan manusia agar memiliki hubungan yang baik di dalam dirinya sendiri dan sesamanya (Estep et al., 2008). Relasi ini adalah mutlak bagi setiap individu agar dapat saling menghargai dan bergantung untuk kemajuan bersama. Orang Yahudi sangat menjunjung tinggi persaudaraan di dalam kehidupan religius mereka setiap hari.

\section{Yesus dan Para Pengikut-Nya}

Konsep guru dalam konsep Timur, berbeda dengan konsepsi modern. Dalam konsep Timur, seorang guru tidak dipandang dari keahliannya saja tetapi karena adanya kharisma keilahian yang didengar dan diikuti oleh murid-murid. Seorang guru tidak selalu bersifat otoriter, tetapi menonjol sifat kebapakan atau keibuannya. Yessi Tamara dalam artikelnya menulis bahwa Yesus sebagai Sang Guru Agung mampu menggunakan media pembelajaran yang ada di sekitar lingkungan mengajar sehingga menjadikannya mudah dipahami dan dimengerti oleh murid Yesus (Tamara et al., 2020). Konsep penggunaan media pembelajaran ini menjadi sangat fleksibel dan menyesuaikan konteks sekitar. Hal ini sesuai dengan konsep Timur yang tidak menyusun pembelajaran dalam paket-paket kurikulum ketat yang terbatas oleh ruang dan waktu.

Dalam tulisan artikel Didache juga disebutkan bahwa Yesus sebagai Sang Guru Agung disebut professional karena mampu mengajarkan kasih agape bukan sekedar secara teori tapi melalui teladan langsung dalam sikap hidup-Nya 
(Kristanti et al., 2020). Tampaklah bahwa pendidikan dalam konsep Tmur, khususnya Yesus mengajarkan segala sesuatu bukan mengedepankan teori dan intelektual saja tetapi juga teladan dalam mengaplikasikan ajarannya dalam tindakan sehari-hari.

Sementara itu, konsep murid dalam konsepsi Timur, memiliki kebebasan untuk memilih guru (rabbi) yang sesuai dengan keinginan dan kebutuhannya. Mereka menempatkan seorang rabbi melebihi orang tuanya sendiri karena ketika mereka memutuskan untuk mengikuti sang guru maka mereka harus meninggalkan orang tua dan pekerjaan sebelumnya (Daugherty, 2013) Muridmurid Yesus merupakan orang-orang yang mendapatkan keistimewaan dipilih oleh gurunya, berbeda pada umumnya. Sebagai murid, mereka belajar semua dari Sang Rabi dan berusaha meniru, dan mengingat semua ajaran dan teladan Yesus.

Ketika mereka dipilih oleh Yesus untuk mengikuti Dia, di dalam Matius 4:19 dinyatakan sebagai "mari berjalanlah di belakang-Ku". Frase ini mengandung implikasi berjalan di belakang Yesus, yaitu menjadikan Yesus sebagai yang berkuasa atas hidup kita. Semua yang diajarkannya dan yang diperbuatnya menjadi kaidah dan pedoman norma bagi kita (Sairin, 2000).
Seymour mengatakan: bahwa tujuan pendidikan kristiani adalah mengikuti jalan Yesus di dalam dunia publik. Pendidikan harus setia dan intens karena sangat penting bagi orang percaya. Pembelajaran dan instruksi terjadi secara langsung dalam keterlibatan pelayanan umat dan bersaksi di tengah dunia masyarakat yang lebih luas (Seymour, 2014).

Jadi murid-murid Kristus diajarkan untuk menjadi saksi-saksi-Nya di tengah dunia publik, melalui pengajaran langsung maupun terlibat langsung dalam setiap aktivitas Yesus setiap kali berjumpa dengan orang-orang di manapun mereka berada.

\section{Tema Utama Pengajaran Yesus}

Ada beberapa tema utama di dalam pengajaran Yesus. Diantaranya adalah mengenai Kerajaan Allah yang datang ke dalam dunia, seruan panggilan untuk bertobat, dan tugas manusia untuk bermisi, mewartakan Injil ke seluruh penjuru dunia (Green et al., 2015). Sidjabat menyatakan pula bahwa kita dapat belajar bagaimana Yesus yang berperan sebagai Rabi, dapat menerapkan pembelajaran dengan menekankan pendidikan di berbagai situasi dan tempat, di antaranya keluarga, di sinagoge, bersama para murid ataupun orang banyak, para pendosa, serta di 
ruang publik seperti di ladang, di pinggir jalan, tepi danau dan bukit (Sidjabat, 2019).

\section{Kerajaan Allah}

Kerajaan Allah yang datang ke dalam dunia memiliki kekhususan. Konsepnya adalah bukan sebuah tempat tetapi sebuah otoritas, kuasa Allah bagi dunia. Budaya manusia di bawah kendali budaya Allah. Ajaran Yesus dirangkum dalam kotbah di bukit dan perumpamaan untuk memberikan value yang berbeda dari nilai-nilai budaya Yahudi (Hermanto \& Enci, 2019). Kadaulatan Allah yang dihadirkan dalam dunia memberikan kepada manusia kesadaran bahwa kerajaan Allah bukan berbicara tentang tempat tetapi tentang kualitas hidup yang ada di bawah pimpinan Allah.

Ucapan bahagia diberikan kepada orang-orang yang lemah lembut, miskin, yang berduka, murah hati, suci hatinya, dianiaya karena kebenaran (Matius. 5:312). Yesus mengajarkan tentang kasih kepada sesama, melampaui nilai-nilai dunia (Matius.6:4), jalan yang benar (Matius. 7:12-14) (Enci, 2018). Kerajaan Allah hadir dalam dunia bagi orangorang yang memiliki hati yang lembut. Kerajaan Allah ini berkaitan dengan perubahan sikap dan gaya hidup yang berbahagia dalam segala keadaan.

\section{Panggilan untuk Bertobat}

Berdasar tulisan Frets Keriapy, mengutip perkataan Fransiskus Irwan Widjaya (Widjaya, 2019) bahwa secara sosiologis, masyarakat Indonesia adalah masyarakat yang religious sehingga mudah menerima kebudayaan yang membawa nilai-nilai spiritual dan religius (Keriapy, 2020). Frets menyetujui bahwa sebagai masyarakat yang religius, semua kebudayaan yang membawa nilai-nilai spiritual perlu dipertimbangkan dan bisa diterima sebagai perbedaan yang harus dihargai.

Yesus mengajak semua orang untuk bertobat, kembali kepada Tuhan dan hidup sesuai dengan apa yang Tuhan kehendaki (Lukas 11 :32). Hal ini menyadarkan bahwa seseorang telah berdosa dan tidak bisa kembali kepada Tuhan jika tidak ditebus dosanya oleh Tuhan. Manusia tidak bisa menutupi kenyataan bahwa dosa tersebut yang memisahkannya dari Tuhan dan tidak ada seorangpun mendapatkan pengampunan dengan cara berbuat baik. Kasih dan perbuatan baik adalah 'akibat' bukan 'sebab'. Manusia yang percaya kepada Yesus dan menerima Dia sebagai Tuhan dan Juruselamat telah menerima keselamatan akibatnya, manusia berbuat baik dan mampu memberikan kasih kepada sesamanya. Yesus memiliki karakter kasih. Demikian pula orang 
yang sudah bertobat akan memiliki kemampuan untuk memberikan kasih bagi sesamanya (Kisah Para Rasul. 10:38), menjadi teladan dalam perbuatan baik, jujur dan bersungguh-sungguh dalam mengajar (Titus 2:7).

\section{Misi Agung}

Panggilan dan tugas bermisi terjadi hingga saat ini. Menurut Matius, "Injil kerajaan ini akan diberitakan di seluruh dunia sebagai kesaksian bagi semua bangsa hingga masa akhir" (Matius. 24:14 lih. Markus. 13:10). The King James Bible menerjemahkan "will be proclaimed" dengan "will be preached." Konkordansi Lengkap Strong menyediakan terjemahan Yunani (2784: kērýssō) sebagai kata kerja "to herald," mengacu pada pemberitaan Injil sebagai firman Tuhan yang mengikat secara otoritatif, membawa pertanggungjawaban abadi kepada semua yang mendengarnya.

Istilah "all" atau semua" mencakup orang Yahudi dan non-Yahudi. Kisah Para Rasul mencatat, Paulus dan Barnabas menyatakan: "Karena inilah yang Tuhan perintahkan kepada kita: Aku telah menjadikanmu terang bagi orang-orang bukan Yahudi untuk membawa keselamatan ke ujung bumi, ketika orang-orang bukan Yahudi mendengar ini, mereka bersukacita dan memuliakan pesan Tuhan, (Kis. 47: 48a).
Akibatnya dan sepanjang zaman, Tuhan secara individu memanggil dan menunjuk misionaris, memberi mereka identitas dan sifat-Nya untuk mewartakan, serta, kabar baik tentang pertobatan, keselamatan, dan kehidupan kekal bagi seluruh umat manusia di dalam Kristus. Tapi panggilannya harus ditanggapi ke ladang misi, bahkan lintasan budaya tidak lagi menjadi penghalang (Tanuwidjaya \& Udau, 2020). Budaya menjadi 'kendaraan'nya dan misi Allah disampaikan sebagai pesan utamanya. Kesadaran manusia sebagai sebagai ciptaan Tuhan yang telah ditebus dapat menjadikan budaya bukan sebagai penghalang dari misi Allah tetapi justru mengarahkan misi Allah pada transformasi masyarakat Ilahi di tengah budaya manusia yang beragam.

\section{Implikasi Teologis Ajaran Yesus}

Dasar teologis pendidikan kristiani adalah alasan alkitabiah tentang pentingnya pendidikan ini sebagaimana terdapat di dalam Amanat Agung Tuhan Yesus (Mat.28:19-20) dengan memperhatikan perintah Tuhan Yesus kepada para murid-Nya sebelum naik ke surga yaitu pergilah, jadikanlah semua bangsa murid-Ku, baptislah dan ajarlah (Panggabean, 2018). Pengajaran inilah yang harus dengan cermat diajarkan kepada semua bangsa secara universal, 
melintasi

$$
\text { berbagai }
$$

budaya

(multikultural).

I Putu Ayub Darmawan dalam sebuah tulisannya berpendapat bahwa amanat agung tersebut bukan sekedar panggilan bermisi tetapi juga ditindak lanjuti dengan pemuridan (I. P. A. Darmawan, 2019). Pemuridan bertujuan agar orang yang dimuridkan juga dapat memuridkan orang lain. Manusia yang dimuridkan tentu saja tidak terlepas dari budaya masing-masing, namun dalam pelaksanaan amanat Agung ini, setiap orang dapat menaruh budaya local sebagai pijakan awal tetapi sasarannya adalah membawa mereka ke dalam pola hidup kerajaan Allah.

\section{Kekristenan bersifat Universal}

Siburian mengatakan bahwa kekristenan berteologi berdasarkan pada konsep umum bahwa seluruh manusia diselamatkan oleh Allah sendiri. Dalam pandangan universalis inklusif dibedakan dengan universalis pluralis. Untuk penganut universalis inklusif, mereka terbuka dengan semua orang dan budaya tetapi masih menunjukkan keunikan dalam kekristenannya. Sementara itu untuk yang universal pluralis, mereka menghargai perbedaan tetapi tenggelam dalam keberagaman relative yang mana masing-masing memiliki kebenarannya sendiri-sendiri (Siburian, 2004).
Pemikiran setiap agama memang memiliki sifat ekslusif dalam ajaran imannya tetapi sikap ekslusif ekstrim justru dapat menghambat misi Ilahi. Universalis dipahami dalam sikap tertentu bahwa semua orang berhak memeroleh keselamatan dari Tuhan sesuai dengan kerelaan dan kemurahanNya.

Nilai-nilai kekristenan berlaku untuk semua orang. Tidak bergantung pada apa ras nya, apa agamanya, apa budayanya. Paul Tillich dalam bukunya mengatakan bahwa bahwa secara khusus setiap orang harus selalu membuka diri dan terhadap agama-agama lain tetapi juga terbuka pada penyataan Allah secara teosentris dalam berteologi (Tillich, 1963). Jelas budaya Allah yang disampaikan dapat melampaui religiusitas budaya manusia. Ketika seseorang belajar kekristenan, mereka akan menjadi tahu dan memahami bahwa Yesus bukan sekedar milik orang Kristen, tetapi untuk semua orang yang mau percaya dan menerima Dia. Semua manusia memiliki hak yang sama untuk menikmati pengajaran Yesus dan menerapkannya di dalam hidupnya. Istilah universal itu sendiri berasal dari unity dan verse, unity in diversity. Sejak awal kekristenan membawa kesatuan dalam keberagaman. Itu sebabnya, asas kekristenan sendiri berpusat pada Kristus 
untuk membawa kesatuan di dalam segala budaya yang berbeda.

\section{Kekristenan bersifat Inklusif}

Inklusifitas berarti sifat kekristenan yang diajarkan adalah membawa perdamaian dan persatuan bagi siapapun. Berkebalikan dengan semangat fanatic yang menganggap dirinya paling benar dan memaksa orang lain untuk sepaham (Green et al., 2015). Yesus sebagai sentral pengajaran dan berita yang diwartakan diberitakan sebagai sebuah kebenaran yang diimani dan tidak dipaksakan kepada orang lain.

Inklusifitas dalam kekristenan juga dapat diartikan bahwa orang Kristen siap untuk berdialog dengan berbagai agama dan budaya lain untuk mengharmoniskan perbedaan yang ada bukan dengan bentuk dasar kompromi dan relativisme (Mulder, 1988). Kekristenan harus menaburkan kasih kepada semua orang tanpa terkecuali, dengan berbaur dalam budaya tetapi mentransformasinya di dalam budaya kerajaan Allah di dunia. Sekali lagi pemahamannya adalah di atas "agama" tetapi melibatkan keyakinan dan perilaku yang mencerminkan Yesus, di mana Yesus tidak membeda-bedakan orang. Semua dilayani dengan kualitas yang sama unggul dan penuh totalitas.

\section{Kekristenan bersifat Misional}

Misional berarti mengemban tugas pemberitaan Injil kerajaan Allah. Tujuannya tentu saja adalah memperkenalkan kehidupan kerajaan Allah bukan sekedar melalui perkataan (verbal) tetapi melalui tingkah laku yang menjadi teladan dalam kehidupan seharihari. Nilai-nilai etika Kristen, perubahan karakter dan pembaharuan akal budi menjadi penekanan utamanya (Green et al., 2015).

Kekristenan tidak lepas dari semangat untuk mewartakan Injil kepada semua orang yang dikenal sebagai sebuah sikap missioner di tengah dunia yang plural (Susanto, 2019). Tugas ini tidak hanya berhenti dalam tugas pewartaan tapi berlanjut dalam konteks menjadikan semua bangsa murid Kristus (I. P. A. Darmawan, 2019). Murid-murid Kristus ini juga mendapatkan tugas melanjutkan pemuridan kepada orangorang lain sehingga dapat dikatakan bahwa Kekristenan selalu bersifat mengundang orang untuk dapat mengikuti teladan Yesus (Green et al., 2018). Tugas bermisi ini adalah bagian peran serta umat Tuhan untuk membawa kekristenan ke segala suku dan bahasa. Misi ini bergerak melampaui setiap budaya local tetapi tetap memperhatikan keunikan dan karakteristik budaya masing-masing (Siburian, 2004). 


\section{KESIMPULAN}

Secara teologis tentang pendidikan kristiani multikultural dapat disimpulkan bahwa misi Allah bagi umat manusia di dunia harus diwujudnyatakan dalam sebuah kesadaran bahwa pendidikan ini selalu bersifat universal melampaui keterbatasan budaya lokal di suatu daerah tertentu. Sifat pendidikan kristiani multicultural adalah menempatkan perbedaan bukan sebagai penghambat, tetapi sebagai jembatan yang harus dilalui agar pesan tersampaikan kepada mereka dan mereka memiliki kebebasan untuk menerima atau menolak.

Teladan pelayanan Yesus di dalam budaya Yahudi dapat diikuti dengan cara terlibat dalam berbagai usaha pewartaan Kabar Baik dengan sikap inklusif dialogis. Artinya siap untuk mengundang sekaligus mempertanggungjawabkan iman kepercayaannya kepada umat yang lain.

Budaya lokal merupakan sarana atau jembatan untuk dapat menyampaikan pesan Allah dengan lebih tulus dan bisa diterima. Allah selalu menggunakan budaya manusia untuk dapat menjelaskan kehendak-Nya bagi umat manusia. Transformasi hidup manusia yang berbasis Kerajaan Allah melampaui budaya lokal. Keberagaman budaya (mulikultur) justru memberikan implementasi iman kepada Yesus dengan lebih membumi karena dalam merumuskannya, budaya turut andil menentukan praksis iman yang berbeda tetapi memiliki esensi iman yang sama.

\section{DAFTAR PUSTAKA}

Banks, J. (2015). Cultural Diversity and Education, Foundations, Curriculum and Teaching. Routledge.

Darmawan, I. P. A. (2019). Jadikanlah Murid: Tugas Pemuridan Gereja Menurut Matius 28:18-20.

Evangelikal Jurnal Teologi Injili

Dan Pembinaan Warga Jemaat, 3 No. 2., 144-153.

Darmawan, P. A. (2019). Pembelajaran Memorisasi dalam Ulangan 6:6-9. Epigraphe: Jurnal Teologi Dan Pelayanan Kristiani, Vol. 3 No., 2127.

Daugherty, J. N. (2013). Discipleship is Jewish. In Heart of God Israel A Light to The Nations (p. 5). Enci, Y. P. (2018). Pengajaran Tuhan Yesus Mengenai Berbahagia dalam Matius 5:3-12. Evangelikal Jurnal Teologi Injili Dan Pembinaan Warga Jemaat, 2 No.2, 115-134. Estep, J. R., M., A., \& Allison, G. (2008). A Theology for Christian Education. B\&H Publishing Group. Green, G. L. (2015). Jesus without borders: Christology in the majority 
world. Choice Reviews Online.

https://doi.org/10.5860/choice.1899 83

Green, G. L., Perdue, S., \& Yeo, K. K. (2015). Jesus Without Borders. Langham Global Library.

Green, G. L., Perdue, S., \& Yeo, K. K. (2018). The Church from Every Tribe and Tongue. Langham Global Library.

Hermanto, B. W., \& Enci, Y. P. (2019). Tema-tema Teologis Kotbah Yesus di Bukit dalam Injil Matius 7:29. Evangelikal, 3 No. 2, 123-135.

John F. Westerhoff. (1976). Will Our Children Have Faith. New York: Seaburry Press.

Keriapy, F. (2020). Pendidikan Kristiani

Transformatif Berbasis

Multikultural dalam Konteks

Indonesia. REGULA FIDEI: Jurnal

Pendidikan Agama Kristen, 5(2), 90.

Kristanti, D., Magdalena, Karmiati, R., \& Emiyati, A. (2020). Profesionalitas Yesus dalam Mengajar tentang Kasih. Didache: Journal of Christian Education, 1 No. 1, 3548.

Kurniawati, M. (2014). Pendidikan Kristiani Multikultural.

Mary, E. (2020). Implikasi Ulangan 5:16 dalam Pendidikan Keluarga. Didache: Journal of Christian
Education, 1 No.2, 141-152.

McKenna, B. (2013). Paulo Freire, Pedagogy of the Oppressed. Critique of Anthropology, 33, 447475.

Mulder, D. C. (1988). Hubungan Antara Dialog dan Misi dalam Konteks Berteologi di Indonesia. BPK. Gunung Mulia.

Nugroho, A. K. (2020). Rekonstruksi Teologis terhadap Pendekatan Pembelajaran Konstruktivisme Sosial. Diligentia: Journal of Theology and Christian Education, $2(3), 33-34$.

Nurcahyono, H. (2018). Pendidikan Multikultural di Indonesia: Analisis Sinkronis dan Diakronis. Habitus: Jurnal Pendidikan Sosiologi Dan Antropologi, 2 No.1, 284.

Panggabean, J. (2018). Pendekatan Praksis-Teologi dalam Fondasi Pendidikan Kristiani. KURIOS (Jurnal Teologi Dan Pendidikan Agama Kristen), 4 (2), 169. Rantesalu, S. B. (2018). Kompetensi Pedagogik menurut Analisis Ulangan 6:7-9 dengan Pendekatan Hermeneutik Schleiermacher. Jurnal Bia: Jurnal Teologi Dan Pendidikan Kristen Kontekstual, Vol.1. No., 153-163.

Sairin, W. (2000). Identitas dan Ciri Khas Pendidikan Kristen di 
Indonesia antara Konseptual dan

Operasional. BPK. Gunung Mulia.

Seymour, J. (2014). Teaching the Way of

Jesus: Educating Christians for

Faithful Living. Abingdon Press.

https://doi.org/https://doi.org/10.151

5/ijpt-2015-0020

Siburian, T. (2004). Kerangka Teologi

Religionum Misioner (I). Sekolah

Tinggi Teologi Bandung.

Sidjabat, B. S. (2019). Meretas Polarisasi

Pendidikan Kristiani: Sebuah

Pengantar tentang Arah Pendidikan

Kristiani di Gereja, Akademia, dan

Ruang Publik. Indonesian Journal

of Theology, 7(1), 15.

https://doi.org/https://doi.org/10.465

67/ijt.v7i1.2

Susanto, H. (2019). Gereja yang

Berfokus Pada Gerakan Misioner.

Jurnal Fidei, 2 (1), 80.

Tamara, Y., Pakasi, A. C., Krismawati,

D., \& Sujoko, E. (2020).

Profesionalitas Yesus Sang Guru

Agung dalam Penggunaan Media

Pembelajaran. Didache: Journal of

Christian Education, 1 No. 1, 65-

76.

Tanuwidjaya, S., \& Udau, S. (2020).

Iman Kristen dan Kebudayaan.

Jurnal Teologi Kontekstual

Indonesia, 1 No. 1, 1-14.

Tillich, P. (1963). Christianity and the

Encounter of the World Religions.
Columbia University Press.

Wasitohadi. (2012). Gagasan dan Desain Pendidikan Multikultur di Indonesia. Scholaria, 2 No.1, 106.

Widjaya, F. I. (2019). Pluralitas dan

Tantangan Misi: Kerangka

Konseptual untuk Pendidikan

Agama Kristen dalam Masyarakat

Majemuk. REGULA FIDEI: Jurnal

Pendidikan Agama Kristen, 4 No. 1, $1-13$. 